\title{
EL COLEGIO DE JESUITAS DE SANTANDER. VIDA MATERIAL Y PATRIMONIO
}

\author{
POR \\ Miguel ÁNGEL SÁNCHEZ GóMEZ ${ }^{1}$ \\ Universidad de Cantabria
}

\begin{abstract}
RESUMEN
El Colegio de los jesuitas de Santander se convirtió en poco tiempo en una de las instituciones más poderosas de la Cantabria del Antiguo Régimen. Desde un principio contó con el apoyo de una gran parte de la sociedad montañesa, sobre todo de la hidalguía rural, además de otros destacados personajes, entre los que hay que destacar a sus fundadores. Si a eso se añade una estricta administración de sus propiedades, que potenció su base económica, no es sorprendente que se convirtiera a mediados del siglo XVIII en una institución en plena expansión, solo truncada por su expulsión.
\end{abstract}

PALABRAS CLAVE: jesuitas; Antiguo Régimen; Santander; vida material; patrimonio.

\section{THE JESUIT COLLEGE OF SANTANDER. STANDARD OF LIVING AND PATRIMONY}

\begin{abstract}
The Jesuit College of Santander rapidly became one of the most powerful institutions in the old regime of Cantabria. From the very beginning it relied upon the support of a large part of the highland community within the region of Cantabria, predominantly the rural gentry, as well as other people of importance and among those, its founders. Adding to this a stringent administration of assets that served to strengthen its economic base, it, unsurprisingly in the mid XVIII century, grew to be a fully expanding institution, cut short only by its expulsion.
\end{abstract}

KEY WORDS: Jesuits; Old Regime; Santander; Standard of Living; Patrimony.

Cómo CITAR ESTE ARTículo / CITATION: Sánchez Gómez, M. Á. 2018. «El colegio de jesuitas de Santander. Vida material y patrimonio». Hispania Sacra 70, 142: 585-599. https://doi.org/10.3989/hs.2018.040

Recibido/Received 09-11-2016

Aceptado/Accepted 18-01-2017

El 2 de mayo de 1767, un mes más tarde de decretarse la «Pragmática de expulsión de los jesuitas», un pequeño grupo de personas entró en la sacristía de la iglesia del extinguido Colegio de jesuitas de Santander con la misión de entregar al Ministro de Marina del puerto -José de Colosía- los Calizes y demas Alhaxas y vestiduras Sagradas, cruzes, misales, Aras, Frontales y todo lo correspondiente para formación de Altar a fin de.... El propósito era entregar a los jesuitas expulsos lo necesario para decir misa en las embarcaciones que deven conducir a dichos Religiosos.... ${ }^{2}$

1 sanchema@unican.es / ORCID iD: http://orcid.org/0000-00028940-6271

2 Archivo Histórico Provincial de Cantabria. (A partir de ahora A.H.P.C.). Sección Centro de Estudios Montañeses. (A partir de ahora C.E.M.). Libro 53. Inventario de los bienes, alhajas, papeles, muebles que poseían los Regulares de la Compañía de Jesús de Santander el día de su extrañamiento, fols. 1-3.
Los encargados de realizar esta labor fueron el Licenciado Manuel Domínguez Urrejolabeitia, Provisor, Vicario General del Obispado y Canónigo con la dignidad de Tesorero de la Catedral; Ignacio Echuz, jesuita; el ayudante de Sacristía, también jesuita, José de Iturzaeta; el maestro platero Alonso del Prado y el escribano que registraba todo lo acaecido, José Antonio Nieto Vela, bajo la supervisión del licenciado Joaquín Nieto Torremocha, abogado de los Reales Consejos.

Estas operaciones continuaron en los días sucesivos, pero no terminarían hasta el 30 de septiembre de ese mismo año. Cinco meses en los que se inventariaron fincas rústicas, inmuebles urbanos, rentas, utillaje de cocina y de labranza, muebles, alimentos, objetos sagrados, libros, documentación diversa, animales domésticos y un largo etcétera, cuyo análisis puede convertirse en una útil aproximación a los niveles de vida de un grupo de jesuitas y que demuestra, entre otras cosas, la complejidad de 
la gestión de un Colegio jesuítico y, al mismo tiempo, comprobar lo que parece una sólida administración que le acabaría convirtiendo en una saneada institución religiosa.

El Inventario presenta dos formas de recoger la información. Los bienes muebles se registraban tal y como se hacía en los inventarios postmortem, con el añadido de la tasación de los objetos inventariados. En el caso de las rentas, se adjuntaba el valor del interés. Para los bienes inmuebles, tanto rústicos como urbanos, la descripción del edificio o de la finca, se acercaba mucho al modelo utilizado en el Catastro de la Ensenada. Con las fincas rústicas se especificaba la extensión, la dedicación, el precio del arrendamiento, las parcelas colindantes y la situación de la propiedad. Cuando se trataba de los inmuebles urbanos, se especificaba la situación en la población, la superficie, los edificios colindantes, el inquilino, su valor y el del alquiler, si lo había.

\section{LOS FUNDADORES}

La trayectoria de las instituciones ignacianas estaba muy marcada por su proceso fundacional. En este sentido no hay un denominador común, ya que junto al apoyo real, de la gran nobleza o de los estamentos más elevados de la clerecía, se encontraban entre los promotores a prominentes miembros del sector comercial, sobre todo a partir de finales del siglo XVII y a lo largo del XVIII hasta su expulsión en 1767, junto a elementos destacados de las oligarquías locales. ${ }^{3}$ En el primer caso, nos encontramos con el Imperial Colegio de Jesuitas de Madrid o con el Colegio de los Ingleses de Valladolid, entre otros. Las elites nobiliarias fueron también importantes contribuyentes a la expansión jesuítica tanto por la Europa católica como por las colonias americanas, además de por otros continentes, Asia y África, como luego veremos. Puede destacarse entre los miembros de la gran nobleza castellana a Magdalena de Ulloa, fundadora del Colegio-Seminario de Villagarcía de Campos y de los colegios de Oviedo y Santander, ya al final de su vida. Caso muy distinto fue la convulsa llegada de los ignacianos a Bilbao con un dilatado proceso de fundación que comenzó en 1604 y acabó en 1674, cuando algunos de los comerciantes bilbaínos apoyaron su fundación. ${ }^{4}$ Tampoco lo tuvieron fácil en Vitoria donde necesitaron dos siglos para conseguir erigir un colegio, como consecuencia de la compleja situación sociopolítica de la ciudad en la que el ascenso de su burguesía urbana, enfrentada a la nobleza local, podía ser puesto en peligro con la llegada de los ignacianos, amén de incidir en el equilibrio económico que mantenía el propio clero vitoriano. ${ }^{5}$ Algo muy distinto fue el proceso de erección del Colegio de San Sebastián en Málaga, en el que el elemento dinamizador fue el obispo Francisco Blanco Salcedo, protector de los jesuitas en todas las sedes episcopales que fue ocupando. El colegio malacitano se inauguró en $1573{ }^{6}$ y sería un ejemplo más de

3 Para una visión amplia de las motivaciones de los fundadores de las instituciones jesuíticas y los procedimientos para alcanzar sus objetivos, aunque más enfocada al ámbito vallisoletano, Vid. Burrieza Sánchez 2003.

4 Porres Marijuan 2009

Benito Aguado 2001.

6 Soto Artuñedo 2001. las fundaciones en las que algunos miembros del alto clero se convirtieron en destacados protectores de los jesuitas, que impulsaron decididamente su llegada a distintas poblaciones. $^{7}$

También en Oviedo hubo problemas entre los religiosos y la universidad ovetense por la cesión de ciertas enseñanzas a los ignacianos, amén de por el pago de los diezmos de los productos que laboreaban los renteros. ${ }^{8}$

Los comienzos del colegio de Tudela tienen alguna semejanza con los de Santander, sobre todo en la sucesión de protectores, ya que, además de los fundadores - un matrimonio, miembro de la oligarquía tudelana, sin hijoshubo otros de distinto rango como el virrey de Navarra, la marquesa de Falces y otros personajes - seglares y eclesiásticos - que entre donaciones en metálico, rentas y fincas rústicas, posibilitaron la puesta en marcha del instituto jesuítico. ${ }^{9}$

En Orduña, en cambio, tenemos entre los fundadores un ejemplo de indiano enriquecido, Juan de Urdanegui y López de Inoso, que fue el encargado de llevar la labor de los frailes a la ciudad - título recibido en 1467- vasca. No obstante, el largo y complejo proceso de fundación de la comunidad jesuítica en la población le impediría ver el resultado de sus desvelos, ya que el colegio no comenzaría su andadura hasta 1689 y Urdanegui moriría seis años antes. Tampoco podría disfrutar en persona del título de marqués de Villafuertes, que recibiría póstumamente en $1683 .^{10}$

\subsection{Los primeros impulsos. Magdalena de Ulloa}

En este sentido, el santanderino Colegio de la Anunciación tendría un planteamiento distinto en sus comienzos, que podrían denominarse "mixtos", ya que estaría fundado inicialmente con el apoyo de la viuda de Luis Méndez de Quijada, Magdalena de Ulloa. Su marido fue uno de los hombres del más próximo entorno del emperador Carlos I, del que era mayordomo, quien le confió a su hijastro, Juan - hijo de Bárbara de Blomberg-, pidiéndole que guardara el secreto por las implicaciones sucesorias que podrían plantear su reconocimiento frente a los derechos de su otro hijo Felipe, habido legítimamente de Isabel de Portugal. Al año siguiente de morir su padre, en 1559, Felipe II reconocería a su hermanastro tal y como se disponía en el testamento del difunto emperador. Durante los catorce años que duró el ocultamiento, Jerónimo - que ese era el verdadero nombre de Juan - había estado alojado y cuidado en el hogar de Luis Méndez de Quijada y de Magdalena de Ulloa en la villa vallisoletana de Villagarcía de Campos y muy cerca de allí, en los alrededores del monasterio de la Santa Espina, tendría lugar el primer encuentro de los dos hermanos, Felipe y Juan, con ocasión de una cacería organizada al efecto.

Sería precisamente Juan de Austria el encargado de reprimir la rebelión de los moriscos del reino granadino, lo que culminó en 1571. Paradójicamente fue en este conflicto donde el hijo de Carlos I perdería a su otro "padre", que

\footnotetext{
7 Atienza López 2009: 67-68.

8 Villafañe 1723: 242-243 y 258-259.

9 Sánchez Barea 2011: 226-227.

10 Porres Marijuan 2012: 313-325.
} 
murió en una de las refriegas contra los moriscos granadinos a finales de febrero de 1570.

Luis y Magdalena se habían casado en 1549 cuando ella tenía 24 años. En los 21 que había durado su matrimonio no habían tenido hijos, luego los títulos pasarían a un hermano de Luis, quien finalmente haría testamento el 24 de febrero de 1570, muriendo un día después.

En la cláusula 57 de sus últimas voluntades, el finado señalaba a su esposa ...que es mejor juntar nuestras haciendas, y hazer algun Monasterio de Frayles, ù Monjas, con tal que no sean de las Descalças, que por ser tan fría la tierra de Campos, no podrían alli vivir, en tal caso doy poder a Doña Magadalena, con mis Testamentarios, para que juntamente con ellos lo dispongan, y ordenen, pues la voluntad de ambos ha sido fazer una dotación perpetua con su hazienda y la mia, y que alli nos enterremos juntos, y tengamos en muerte la buena compañia, que tuvimos en vida...(sic). ${ }^{11}$

El cadáver de Luis de Quijada sería sepultado provisionalmente en el convento de Jerónimos de la Ciudad de Baza hasta febrero de 1572 en que sería trasladado a Villagarcía de Campos. El coste del traslado de Baza a Villagarcía llegó a los 2.000 ducados. En el viaje participaron 12 jesuitas. ${ }^{12}$

La viuda tenía 45 años al morir su marido y se retiró seis meses al convento de los Padres Recoletos de San Francisco del Abrojo, a unos kilómetros de Valladolid. Aunque en un principio consideró ingresar en el monasterio también vallisoletano de Las Huelgas, en el que era abadesa una hermana de su difunto marido, Ana Quijada, un pleito entre ambas por la herencia de Luis le hizo desistir de esta primera intención.

Ya de regreso en Valladolid, ocupó la casa de un sobrino de su difunto marido, el conde de Miranda, que había sido virrey de Nápoles. Acudió con frecuencia al Colegio de jesuitas de San Antonio en donde eligió como confesor al padre Juan de Prádanos. También acudía a Villagarcía en donde el padre Baltasar Álvarez era rector, precisamente por intercesión de Magadalena Ulloa, para asistir a sus ejercicios espirituales. El ascendiente del padre Álvarez sobre la viuda de Luis Quijada la conduciría al deseo de construir un colegio jesuítico en Villagarcía. ${ }^{13} \mathrm{~A}$ partir de aquí comenzó el proceso de construcción del edificio, para lo cual se elaboró en primer lugar un inventario de bienes raíces y rentas de ambos consortes que alcanzó los cinco millones de reales con los que, además de sumar las cantidades que ingresó durante los veintiocho años que sobrevivió a su marido, pudo construir los Colegios de Villagarcía, Oviedo y Santander, además del Hospital de la Magdalena en la propia Villagarcía. Solo el Colegio de esta villa y su iglesia, junto con la dotación, supuso un costo de 3.080 .000 reales. Además, realizó otras fundaciones y obras benéficas. ${ }^{14}$

Posteriormente Magdalena levantó un noviciado junto al Colegio y la iglesia, además de una nueva capilla en el templo, no sin resistencia del clero parroquial de la villa y de la mayoría de los ocho testamentarios de su marido. Pero la muerte de cinco de ellos y la renuncia de otro, junto con la inhabilitación de la anteriormente citada hermana del

\footnotetext{
11 Villafañe 1723: 82-83.

12 Ibídem: 90.

13 Puente 1615

14 Villafañe 1723: 99-100
}

difunto, dejó las manos libres a la viuda para la realización de sus planes de emplear toda su herencia en lo que quisiese.

Pero pronto volvieron a surgir problemas que obligaron a Magdalena a consultar al Consejo Real y, posteriormente, a expertos de las universidades de Salamanca y Alcalá, que resolvieron a favor de la viuda de Luis Quijada.

El Colegio de Villagarcía sería la cabeza de todas las fundaciones vinculadas con los jesuitas, sería el Protector y defensor de..., como de los Colegios de Santander, Oviedo, y del Monasterio de la Penitencia en Valladolid..$^{15}$ El convento vallisoletano se haría cargo de todas los bienes y rentas si los colegios de Oviedo y Santander se deshiciesen o no cumpliesen conforme a lo conmigo estipulado. Finalmente, Magdalena se reservaría setecientos y tantos mil maravedís por todos los días de mi vida; sin embargo, en esta última cláusula deslizó una frase - previa a la cantidad reseñadaque parece apuntar hacia una garantía de que esa cantidad no se desviara de su finalidad: y con que yo la dicha Doña Magdalena, sin dependencia, ni poder del dicho Colegio (de Villagarcía), he de gozar, y cobrar las dichas setecientas y tantas mil maravedís por todos los días de mi vida, y no mas.. (sic). ${ }^{16}$

Así pues, la figura impulsora de estas instituciones ignacianas norteñas fue Magdalena de Ulloa. La herencia que recibió de su marido, junto con su propio pecunio (en conjunto 455.000 ducados), ${ }^{17}$ le permitió la fundación de las tres instituciones ignacianas. El fin principal que esta santa señora tuvo en estas dos fundaciones fué el de potenciar las misiones de nuestra Compañía para la enseñanza y socorro espiritual de estas Montañas, por la fama e informes que tuvo de algunos de la misma Compañía que las habían corrido algunos años antes haciendo dichas misiones y hallando en ellas graves ignorancias y necesidades espirituales dignas de este remedio ( $\mathrm{sic})^{18}$... porque observando lastimados los padres, que de uno, y otro Colegio, corrían los más ásperos parages de entrambas montañas, en el importante, y sagrado ministerio de las Missiones, la indecencia, y gran falta de reverencia con que see guardava el Santísimo Sacramento en las mas Iglesias, por la pobreza de sus fabricas, en que entrava a la parte, como suele la poca aplicación o devoción de sus curas... (sic). ${ }^{19}$

En 1594 Magdalena había escrito una carta al Padre General Claudio Acquaviva solicitándole la creación de un Colegio en Santander, petición que debió obtener rápidamente, porque en septiembre de ese mismo año firmaba la escritura de fundación del Colegio santanderino, adjudicándole una renta de 1.600 ducados en juros. En este caso, además de erigir un centro de difusión de las misiones jesuíticas, en las que se perseguía el cambio y la mudanza de vida y costumbres, de las conductas y de las actitudes de los que ya pertenecían a la Iglesia, ${ }^{20}$ también pesó el hecho de ser Santander un puerto desde donde podrían penetrar hacia el interior de Castilla las ideas protestantes, ${ }^{21}$ importante

\footnotetext{
15 Ibídem: 144-145.

16 Ibídem: 149-150.

17 Burrieza Sánchez 2004: 111-112.

18 Cascón 1952: 5-6.

19 Villafañe 1723: 213.

20 Burrieza Sánchez 2004: 164.

21 No obstante, la elección se tomó tras ser visitadas las cuatro poblaciones costeras más importantes - San Vicente de la Barquera,
} 
preocupación que también impulsó la fundación del colegio jesuítico de Bilbao. ${ }^{22}$ Este mismo peligro, la penetración de estas influencias heréticas por la vía cantábrica fue la que movió, además de la dilatada extensión del arzobispado burgalés y la deficiente atención de sus prelados a los territorios montañeses, a Felipe II a separarlos de aquella archidiócesis mediante la creación del obispado, algo que no ocurriría hasta la llegada al confesionario regio del padre Francisco de Rávago, ya a mediados del siglo XVIII. ${ }^{23}$

No es extraño, pues, que en el recorrido que hizo la comisión se encontrase un retrato de la fundadora en un sitio principal del convento como de vara y cuarta y una de ancho con su marco de madera pintado de negro, que se halla sobre la Puerta del costado de la Iglesia, cuyo cuadro tiene la Pintura en Lienzo, y el retrato de la fundadora del Colegio (sic), que sería tasado en 4 reales. ${ }^{24}$

\subsubsection{Los traumáticos primeros pasos}

La llegada de los ignacianos coincidió con la arribada al puerto santanderino de varios barcos provenientes de Flandes, que transportaban enfermos de peste. La epidemia se propagó rápidamente entre la población, falleciendo numerosos vecinos. Los jesuitas se prodigaron en el cuidado de los enfermos y el propio primer Rector del Colegio, Pedro de Elorrio, fallecería víctima de la enfermedad. ${ }^{25}$ Su sucesor, Pedro de Frías, también contraería la enfermedad, pero no moriría por su causa, prosiguiendo su labor en otros colegios, en alguno de los cuales - Bilbao y Palencia - llegaría a ser Rector. Tanto en Santander como en Oviedo, la peste de 1597-99 produjo muchas bajas, no solo entre la población sino también entre los propios jesuitas, calculándose que en toda la provincia castellana la Compañía perdió un $12 \%$ de sus miembros, sobre todo en los dos Colegios del norte. ${ }^{26}$ En Santander murieron por esta causa cinco de los siete jesuitas que llegaron en esa primera época. ${ }^{27}$

En todos los pueblos de Cantabria, pero sobre todo en las poblaciones costeras, la peste se extendió rápidamente. En la villa santanderina, hasta finales de 1597 habían muerto más de 1.000 personas. Casi las tres cuartas partes de los vecinos habían huido o muerto de hambre o de peste. ${ }^{28}$ Para ayudar en estas dificultades, los jesuitas gastaron cerca de 3.000 ducados de limosnas ofrecidas por Magdalena de Ulloa.

No debió generarse mucha resistencia a la erección de un colegio jesuítico en la villa santanderina. ${ }^{29}$ En las actas municipales no se detectan situaciones de este tipo y el incendio de 1941 hizo desaparecer cualquier atisbo

Santander, Laredo y Castro Urdiales - por un jesuita, del que no se ha conservado la identidad, que fue quien emitió un informe en el que se aconsejaba la elección de Santander. Vid. Fernández Martín 1998: 189.

22 Porres Marijuan 2009: 506-511.

23 Alcaraz Gómez 1995: 266-267.

24 A.H.P.C. Sección C.E.M. Libro 53, fol. 28.

25 Sobre el papel de los jesuitas en los momentos de crisis demográficas, situación vinculada al sacramento de la confesión, Burrieza Sánchez 2004: 145-148.

26 Burrieza Sánchez 2009: 531.

27 Puede verse también otro testimonio de estos iniciales y difíciles pasos de los jesuitas en Santander en Cascón 1952: 12

28 Lanza García 1991: 254-262.

29 Fernández Martín 1998: 198. documental de rechazo del cabildo de la colegiata de San Emeterio y San Celedonio - los Santos Mártires- y futura sede de la mitra santanderina a la implantación de los jesuitas. Los datos recogidos en el propio inventario de 1767, indican más bien una cierta colaboración con el cabildo santanderino, como se verá más abajo. En cambio, sí existen datos de la gran resistencia que el clero secular local y algunos poderosos presentaron al establecimiento de conventos y monasterios de las distintas órdenes que quisieron establecerse en algunos puntos de la geografía montañesa: Laredo, Santillana, Soto-Iruz, Potes o Las Caldas, entre otros, siendo casi siempre los franciscanos o los dominicos los objetos del rechazo. ${ }^{30}$

Como en el caso de la mayoría de los conventos y monasterios creados desde la Edad Media, la expansión de los colegios jesuíticos se basó en el apoyo de la Corona y de las grandes familias nobles que utilizaron sus grandes recursos para levantar edificios, apoyar financieramente o incorporar a sus hijos en los estudios dispensados en los colegios. Dada la tardía implantación de los ignacianos en los países católicos, en el quicio de los siglos XVI y XVII, y la amplitud de su expansión, nos encontramos con que muchas casas se fundarían ya en las últimas fases del reinado de Carlos II. Es por esta razón en parte, por la que en el caso de las instituciones ignacianas aparecerán en escena otros grupos de apoyo como los comerciantes ${ }^{31} y$, posteriormente, miembros de la administración real en los territorios ultramarinos, signo de los cambios propulsados por una tibia recuperación de la España finisecular, asentada, tras la crisis de la Guerra de Sucesión, por el giro impulsado por la nueva dinastía, una coyuntura que también se comprobará más abajo en el caso del Colegio de Santander.

Además de los anteriormente reseñados, tenemos muy pocos datos acerca de los primeros avatares del Colegio de Santander. Conocemos que en los años 20 de la siguiente centuria las obras del Colegio y de la iglesia ya habían concluido y que unos años antes se habían recibido las reliquias de San Vidal, un mártir de los primeros pasos del cristianismo en Roma, en una arquita en la que, además, se guardaban restos de otros santos. ${ }^{32}$ Las reliquias de los primeros mártires cristianos eran las preferidas de los jesuitas cuando erigían sus colegios. ${ }^{33}$

\subsection{La consolidación. El marqués de Villapuente}

Es especialmente reseñable, no obstante, la fundación en 1643 de la Congregación de Nuestra Señora del Perpetuo Socorro, siendo su primer Abad Juan de la Puente y Peña. Es el primer indicio de la conexión con la familia Puente Peña. Juan era el hermano mayor de José de la Puente Peña Castejón y Salcines, poderoso indiano, que acabará convirtiéndose

\footnotetext{
30 Fonseca Montes 1996: 199-204.

31 Aunque este grupo socioeconómico ya había hecho acto de presencia anteriormente en las fundaciones jesuíticas como fue el caso del riquísimo Rodrigo de Dueñas y algunos otros mercaderes de menor porte que tuvieron parte fundamental en la erección del colegio de Medina del Campo. Vid. Burrieza Sánchez 2007: 269-271.

32 Fernández Martín 1998: 200-201. La "arquita" que contenía las reliquias de San Vidal se hallaba en un «retablo y alttar llamado del Populo» en un lateral del altar mayor en 1767. C.E.M. fol. 15 vta.

33 Burrieza Sánchez 2004: 93.
} 
en el nuevo protector del Colegio santanderino a principios del siglo XVIII, aunque en realidad su mecenazgo jesuítico se extenderá por los cuatro continentes conocidos. Esta institución recibió un gran apoyo desde sus primeros comienzos, pues tuvo 500 congregrantes. ${ }^{34}$

Las congregaciones fundadas por los ignacianos en sus colegios y en los lugares por donde pasaban, trataban de reforzar la visión misional que de sus actividades tenían los jesuitas. Para ello intentaban captar a los personajes más destacados de los lugares en los que desarrollaban su labor, con el fin de utilizarlos como referentes sociales, haciéndoles participar en actos públicos como la recogida de limosnas o la penitencia. ${ }^{35}$ Pero, además, la conexión con la familia Puente Peña acabará resultando un extraordinario negocio para la comunidad jesuítica santanderina en particular $y$ para toda la orden en general.

En el libro de Juan de Villafañe La limosnera de Dios: relación histórica de la vida, y virtudes de la excelentísima Señora doña Magdalena de Ulloa Toledo Ossorio y Quiñones...fundadora de los colegios de Villagarcía, Oviedo y Santander, ${ }^{36}$ se hace un minucioso recorrido por los últimos tramos de la vida de la fundadora y patrona del Colegio de Villagarcía de Campos y del proceso de su fundación. No hay demasiadas noticias, en cambio, de las instituciones ovetense y santanderina, quizá porque ambos procesos coincidieron con la fase final de la vida de Magdalena, fallecida en 1598. Pero en realidad, el libro de Villafañe, publicado en Salamanca en 1723, estaba dedicado a su segundo fundador, al que ofrece un largo proemio en el que se descubre la verdadera relación del marqués con el Colegio santanderino.

D. José, riquísimo indiano novohispano, había emigrado a México en 1678 a la edad de 12 años, reclamado por su tío Francisco de la Peña Salcines, entre otras cosas era caballero de Calatrava desde 1688, capitán de las reales guardias de la ciudad y su alcalde honorario, ${ }^{37}$ instalado ya en la capital del virreinato como un importante mercader que designó a su sobrino para manejar su más que considerable hacienda. En la capital, José, que llegó a ocupar el cargo de Alcalde Mayor, tendría un destacado papel en la derrota de la rebelión de los indios de la capital mexicana en 1692, resultando herido. Su tío ya le había confiado la administración y cuidado de sus haciendas en el norte del país. José de la Puente se haría con el control del abastecimiento de carnes de Chalco - una de las zonas más pobladas del valle de México, junto a la capital- como obligado. Se casaría en 1717 con la hija de su tío, Gertrudis de la Peña, Marquesa de las Torres de Rada. ${ }^{38}$ Al morir su tío-suegro, su patrimonio quedaría en poder de su hija, pero José lo administraría acrecentándolo hasta convertirse en uno de los mayores terratenientes novohispanos. Parece que el núcleo de su negocio era la cría de ganado. Llegó a tener 150.000 cabezas de ovino y más de 40.000 de vacuno. Por los primeros obtendría unos rendimientos anuales de 1.200 .000 reales. Seguramente la base de su economía giraría en torno al abastecimiento de

\footnotetext{
34 Fernández Martín 1998: 201.

35 Rico Callado 2003: 113; Burrieza Sánchez 2004: 148-150.

36 Biblioteca Municipal de Santander (A partir de ahora B.M.S.). Ms.

37 Sanchiz Ruiz 2009: 139.

38 Ibídem: 136.
} 1.473 . carne, de lana y cueros a la capital de la colonia y en otras actividades comerciales, pero no parece que interviniera en los negocios mineros ya que el pico de las actividades extractivas se iniciaría a mediados del XVIII, mientras que el Marqués de Villapuente moriría en Madrid en 1739.

No ha podido encontrarse el testamento del marqués, pero en 1727 fundó unas importantes obras pías, de carácter educativo una, otra para sostener una capellanía en la que celebrar misas piadosas y una tercera para dotar a las hijas de sus parientes. Todas ellas respaldadas con 330.000 reales. ${ }^{39}$

Pero toda esta impresionante trayectoria, no hubiera sido posible sin el respaldo de la nueva dinastía a la que prestó destacados servicios que comenzaron por su participación en la represión de la rebelión de los indios en la capital del Virreinato de Nueva España en 1692, como se ha indicado anteriormente, lo que le valdría el hábito de Santiago, en cuya Orden ingresaría en 1696. Ese sería el primero de los varios servicios a la Corona del futuro marqués. Previamente había servido a lo largo de ocho años como soldado en la armada de Barlovento. Durante las guerras finiseculares del reinado de Carlos II, Veracruz fue un centro de atracción de todos los enemigos con los que tuvo que enfrentarse España en esos años. Así en diciembre de 1695, ante la amenaza de invasión de una flota francesa, José armaría una compañía de infantería a su costa y sería encargado por el virrey de su dirección, lo cual significaba un reconocimiento de sus méritos anteriores. Los franceses se retirarían y tres años después José recibió del virrey, José Sarmiento de Valladares, el título de Capitán de la Infantería Española. Tras la vuelta de uno de sus frecuentes viajes a la Península, ingresaría como miembro del cabildo y fue regidor, alcalde honorario de primer voto de México y alcalde de Mesta; todo ello entre 1700 y $1701 .{ }^{40}$

Una coyuntura bélica similar y con el mismo escenario, se presentaría con ocasión de la Guerra de Sucesión. Esta vez el enemigo sería la flota inglesa, ante lo que de la Puente armaría una Compañía de Caballos de 50 hombres, por lo que recibiría la graduación de Capitán de Caballos Corazas. En el mismo conflicto armó y sustentó durante más de un año a un Regimiento de 500 soldados. ${ }^{41}$ El gasto esta vez, al que hubo que añadir el mantenimiento de un hospital, alcanzó los 400.000 reales. En 1703, estando nuevamente en la península, recibiría de Felipe $V$ el grado de Maestre de Campo de la Infantería Española. En ese momento ofreció al Consejo de Guerra armar un tercio de 500 hombres completamente equipados y mantenidos a su costa. No es extraño que poco después recibiera el título de marqués de Villapuente de la Peña. En esta concesión pesarían igualmente sus obras benéficas y asistenciales.

Estas y otras actividades relacionadas con el apoyo a labores de carácter confesional, le llevaron durante los últimos años de su vida a viajar por distintos lugares de España e Italia y a apoyar a los franciscanos y, sobre todo, a los jesuitas, dedicando grandes cantidades de dinero a construir edificios y obras y a fomentar la labor misional en África, donde sufragó la redención de cautivos, Asia (Filipinas,

\footnotetext{
39 Lanza García 1992: 166.

40 Sanchiz Ruiz 2009: 140.

41 Ibídem: 142-143.
} 
India, China y Japón), además de América, en especial, apoyando la labor de los jesuitas en las Californias, ${ }^{42}$ y en Europa. Después de un viaje por varios lugares apoyando sus fundaciones y las actividades de los jesuitas, moriría en Madrid, en el Imperial Colegio de la Compañía de Jesús, en febrero de 1739 a los 69 años, después de pedir y ser admitido en la Compañía de Jesús. Si Juan de Villafañe le había denominado en vida Tesorero de Cristo, el también jesuita P. Alegre en su Historia de la Compañía de Jesús en Nueva España le calificaría como Tesorero común de toda la universal Compañía de Jesús y de todo el orbe cristiano. ${ }^{43}$

En uno de sus varios viajes a la Península edificaría el palacio de Villapuente en Muriedas, hacia 1727 , hoy sede del ayuntamiento de Camargo. ${ }^{44}$

Lo que sí parece claro es que no se cumplió la máxima popular en el siglo XVII que mantenía que para ganar el cielo, ya no se necesitaba más que dejar a los regulares cuanto tenía cada uno en el suelo y en la bolsa, y, en concreto para el caso del fundador del colegio de Orduña, el rico indiano Juan de Urdanegui López de Inoso: después que muriera en manos de sus piadosos directores ...sus nietos andan por España sin tener hoy que comer, ${ }^{45}$ ya que la familia Puente no debió flaquear, puesto que décadas más tarde, en 1789, el hijo del segundo marqués de Villapuente pudo casarse con la heredera de la familia Abarca, una de las más poderosas de la Cantabria antiguorregimental, instalada en la ascendente ciudad de Santander.

Es el P. Alegre quien señala al Marqués de Villapuente como refundador del Colegio de Santander reedificó y dotó de nuevo el colegio de Santander, ${ }^{46}$ aportando una cantidad de 42.000 pesos, aceptando la designación de Patrono. ${ }^{47}$

Así que el Colegio santanderino tuvo dos fundadores, dos protectores. Uno, Magdalena de Ulloa, viuda de uno de los nobles castellanos más influyentes de finales del siglo $\mathrm{XVI}$, representante de la vieja nobleza de origen medieval, que apoyó a Carlos $V$ en la guerra de las Comunidades y a Felipe II en la lucha contra los moriscos de las Alpujarras. Después de la muerte de su marido se entregó en el apoyo a los jesuitas, aunque en el testamento de Luis no se especificara la orden sobre la que se habrían de imponer cantidades para su memoria y la salvación de su alma.

El segundo de los fundadores fue prácticamente la antítesis de Magdalena. Rico comerciante y ganadero novohispano, emergido de la humilde hidalguía rural montañesa, se ganó el favor real armando tropas a su costa para defender los derechos de la nueva dinastía borbónica y en defensa del dominio colonial de la Nueva España. A lo largo de su estancia en los territorios mejicanos, apoyó la expansión jesuítica por el noroeste del país y por otros territorios extraeuropeos. Su natal Montaña fue también objeto de sus atenciones. El Marqués de Villapuente, sería en gran medida, un paradigma de la neonobleza borbónica, a medio camino entre el ejercicio militar y los cuatro pilares en que se basó, como signo de los

42 Sobre la vinculación entre el marqués de Villapuente y la compleja evangelización del sur de California por parte los jesuitas, vid. Bernabéu Albert 2011: 157-158.

43 Alegre 1841-1842, T. 3: 279, cfr. Sanchiz Ruiz 2009: 142.

44 Sanchiz Ruiz 2009: 146.

45 Porres Marijuán 2012: 310.

46 Sanchiz Ruiz 2009: 144 (citando al P. Alegre).

47 Jado Canales 1957: 695-696. nuevos tiempos, su ascenso social: el comercio ultramarino, la administración real, la explotación agropecuaria de extensos latifundios y, aunque no parece que sea el caso que nos ocupa, una intensa actividad minera.

Los eficaces sistemas jesuíticos de captación de apoyo de los grupos privilegiados a los que conducían a buscar destinos más perpetuos que las meras donaciones pías que solían hacer en sus testamentos, llevaban a sus poderosos protectores a apoyar el desarrollo de los colegios locales. ${ }^{48} \mathrm{En}$ el fondo de estas atenciones desarrolladas a lo largo de gran parte de la vida del sujeto y en especial en los momentos previos a hacer testamento, no solo se trataba de facilitar el "pasaporte" más seguro hacia la anhelada salvación, sino que igualmente se perseguía captar ciertas fortunas económicas que potenciasen la expansión de sus colegios.

\section{El apoyo social. la Congregación de nuestra Señora} DEL SOCORRO

En la inspección del archivo de la Congregación de Nuestra Señora del Perpetuo Socorro, según se anotó en el inventario general, apareció toda la documentación de esta institución que, no obstante, no ha llegado íntegramente hasta nosotros. Sin embargo, sí se dispone del registro de sus miembros en el primer tercio del XVIII, cuando la congregación estaba ya a punto cumplir un siglo de existencia. La documentación conservada se limita a enumerar los integrantes de la Congregación en un periodo de tiempo que abarca los meses de julio a noviembre de 1738.

Sin poder profundizar mucho por lo escueto de la información - nombre y apellidos, en escasas ocasiones dos, "don" o "doña", título nobiliario si lo hubiere y, en el caso de los religiosos, titulación-, la nómina de componentes de la Congregación nos delinea algunos perfiles del Colegio santanderino nada baladíes ni comunes con los de otras instituciones similares.

Hay varios aspectos llamativos en lo que a sus integrantes se refiere. En primer lugar, la larguísima nómina de miembros de la institución, un total de 6.494; lo cual nos lleva a dudar de que en poco más de cuatro meses se produjera tal alud de adhesiones. Podría pensarse, más bien, que se trataba de personas que ya eran anteriormente miembros de la Congregación. Debe tenerse en cuenta, según se señaló más arriba, que la institución se había fundado a mediados de la centuria y que en escaso tiempo alcanzó el medio millar de integrantes.

En segundo lugar, el solo número de sus miembros ya indica claramente que no comprendía únicamente la ciudad de Santander, que en esos momentos apenas alcanzaba los 4.000 habitantes. ${ }^{49}$ Antes bien, los datos de los que disponemos hasta el momento, permiten comprobar que casi todas las jurisdicciones y villas que formaban parte de la Cantabria de la época tenían al menos una familia integrada en la Congregación. De todos las territorios que componían

48 Burrieza Sánchez 2009: 538-539 y 543-544.

49 Lanza García, R. 1991: 141. La cifra es la suma de la población del casco urbano más la de los Cuatro Lugares: Cueto, Monte, San Román y Castillo. 
la Cantabria antiguorregimental, solamente una no tenía representación alguna en la Congregación, la Provincia de Liébana. No alcanzamos a comprender esta excepción, salvo que tuviera algo que ver con la circunstancia de que ese territorio estuviese integrado en aquella época en el obispado de León.

El tercero de los aspectos que se derivan del listado de componentes es que casi todos sus miembros pertenecen a las elites montañesas, concretamente a la pequeña nobleza no titulada. De los casi 6.500 efectivos, 1.460 eran "dones" y "doñas"; es decir, casi el $25 \% .{ }^{50}$ Pero una gran mayoría del resto eran parientes de los anteriores, segundones y ramas secundarias del linaje principal. Al frente de este amplio elenco de notables rurales y urbanos, se encuentran los más destacados miembros de la nobleza titulada regional. Como era de suponer, el marqués de Villapuente y su amplia parentela nutren las filas de la santanderina Congregación de Nuestra Señora del Perpetuo Socorro. Asimismo el marqués de Valbuena del Duero - Antonio Ibáñez de Riva Herreray su esposa. El III Conde de Mansilla, Manuel Antonio Campuzano y Junco, y su cónyuge Antonia de Peralta y Menéndez se encontraban también entre los congregantes. El V marqués de Villatorre, Antonio Bustamante Bergaño, estaba igualmente integrado en esta organización de apoyo jesuítico.

Junto a este bloque de notables montañeses, encontramos a miembros del clero entre los que puede destacarse al arzobispo de Burgos, Manuel Samaniego y Jaca, y al abad de la Colegiata santanderina de los Santos Mártires, Lucas Cuartas Castro, lo que parece una prueba más, sobre todo en este último caso, del apoyo que también el clero secular santanderino dispensó a los ignacianos. Pero en lo que se refiere al clero regular, tampoco parece que hubiese serias reticencias que no se han detectado en la documentación manejada. Algunos frailes y monjas de distintas órdenes religiosas engrosaban los apoyos a los jesuitas, si bien es verdad que muchos de ellos eran vástagos de los linajes más descollantes de Cantabria. No cumplía esta condición el prior del convento dominico de Las Caldas, Antonio Abad, del que no consta que tuviera vínculos familiares con los notables locales. Este monasterio era el más influyente de todo el territorio, ${ }^{51}$ fundado por una de las familias más descollantes de la Montaña, los Velarde - ampliamente representados entre los congregantes-, y la inclusión de su abad como miembro de la Congregación parece evidenciar la ausencia de rechazo de los ignacianos en el territorio montañés, incluso entre el clero regular más asentado.

\section{VIDA MATERIAL Y PATRIMONIO}

A lo largo de 26 jornadas, la primera el 2 de mayo y la última el 30 de septiembre, la comisión compuesta por las personas reseñadas al comienzo de este trabajo fue inventariando las diversas pertenencias de los jesuitas

50 Los "dones" y "doñas" constituían el grueso de los elementos más notables de la hidalguía montañesa a lo largo del siglo XVIII y gran parte del XIX, sobre todo en los ámbitos rurales. Sobre las bases económicas sobre las que sustentaban su dominio y sus comportamientos sociales, culturales y religiosos vid. Sánchez Gómez 2013.

51 Fonseca Montes 1996: 217-218. santanderinos, desde los objetos litúrgicos, los censos y otras rentas, hasta los muebles, objetos decorativos y libros, pasando por las propiedades rústicas y los edificios, no solo en la ciudad santanderina sino en todos aquellos lugares del obispado de Santander donde los frailes tenían propiedades. Gracias a este exhaustivo inventario podemos conocer con gran exactitud las bases económicas del Colegio santanderino - si exceptuamos limosnas y donaciones $-y$, por otro lado, aproximarnos a los modos de vida de sus habitantes. Las visitas de la comisión encargada de hacer inventario comenzaron el 2 de mayo, como se indicó más arriba. Inicialmente algo más de un centenar de objetos como casullas, albas, corporales, además de misales, manteles, cruces, purificadores y otros objetos de culto fueron inventariados. También se separaron casi medio centenar de otros como calices, patenas y vinagreras de plata con un peso de casi siete kilos que se salvarían de la requisa final. Ello implicó que la comisión entrase en la Sacristía del Colegio donde registraron los objetos que encontraron y que serían enviados al Ministro de Marina para que a su vez los entregara a los jesuitas que estaban a punto de partir hacia el exilio.

Ese mismo día se continuó el inventario de basos sagrados y alhajas de la Iglesia y Sacristía para lo que se unieron a la anterior comisión un comerciante de casi seguro origen francés, Juan de Loustalet, que asista igualmente para la precisa explicación de las telas y demás ornamentos que se inventarien. También se incluyó al platero arriba reseñado cuya misión era pesar los objetos de oro y plata. En la sacristía, además de los artículos anteriormente separados del resto, se encontraron otros como lámparas, custodias, cruces, coronas, rosarios, manos (reliquias) e incensarios hasta un total de 64 objetos, todos de plata, cuyo peso superaba los $55 \mathrm{kgs}^{52}$

En el mismo lugar se hallaron diversas cantidades de dinero, alguna de ellas bastante crecida, como la que alcanzó los 212.249 reales y 20 maravedises y otra suma bastante mayor -406.887 reales y 12 maravedises - que, según el procurador, eran un depósito de Pedro Negrete, un comerciante de origen vascongado residente en Indias. Una cantidad menor, 5.362 reales y 8 maravedises, se declaró como de propiedad de dicho Colegio y sus individuos. Los dineros se depositarían en un arca de dos llaves. Además se inventariaron 190 reales y 4 maravedises y dos lámparas grandes de plata, fábrica de Indias, de las que no se cifra su peso, además de otros varios objetos también de plata, que eran de los congregantes ciudadanos. ${ }^{53}$

El papel como intermediarios de capitales de los jesuitas se atisba en el caso del legado de Pedro Negrete Sierra, que había nacido en Aldeacueva, en las Encartaciones vascongadas, en 1681. En cierto modo, su vida se asemejaba a la del marqués de Villapuente. Pedro marcharía a Nueva España reclamado por su tío y aunque se inició en la carrera militar, en la que pronto alcanzaría el grado de capitán, acabaría dedicándose a los negocios en los que tuvo éxito, engrosando una gran fortuna que aplicaría abundantemente en fundaciones benéfico-docentes. Moriría en 1749 en la ciudad de México, siendo enterrado en la capilla de Nuestra

\footnotetext{
52 A.H.P.C. Sección C.E.M. Libro 53, fols. 4-6 vta.

53 A.H.P.C. Sección C.E.M. Libro 53, fol. 23 vta.
} 
Señora de Aránzazu del convento Grande de San Francisco. En su testamento había señalado la importante cantidad de 1.875.000 reales para fundar diversas obras pías en su pueblo natal, de los que 750.000 servirían para construir las instalaciones del colegio de jesuitas y el resto para comprar tierras cuyas rentas sirviesen para el sustento del convento y de sus habitantes, ya que como en otras circunstancias y en otros escenarios, los lugares de las nuevas fundaciones conventuales debían ser prósperos y con la suficiente capacidad para generar limosnas. ${ }^{54}$

Sin embargo, los ignacianos rechazaron el ofrecimiento, posiblemente por la pobreza del entorno en el que se iba a erigir el colegio, argumento que se utilizó en numerosos casos en los que también se desestimó la fundación de un instituto jesuítico. ${ }^{55}$ Así que gran parte del legado se destinó a otros menesteres como la construcción de una casa-escuela para los niños de la zona o la creación de una capellanía dotada con 90.000 reales. Se repartió igual cantidad entre todos los vecinos de Aldeanueva y se dotó a la parroquia para hacer fija la asistencia religiosa con 60.000 reales. ${ }^{56}$

Pero su legado más reseñable fue la reconstrucción de la iglesia parroquial de San Bartolomé de Aldeacueva, verdadero destino de la cantidad encontrada en el colegio santanderino. La obra de reconstrucción del templo carranzano no se retomó hasta 1779 , sin que hasta el momento se hubiese conocido la causa de este retraso. ${ }^{57}$ Parece, entonces, que la retención de los más de 400.000 reales del legado Negrete por los jesuitas santanderinos - sin que se pueda conocer el porqué de esa situaciónfue la verdadera razón del medio siglo de retraso que medió entre la muerte de Pedro y el comienzo de las obras, algo que parece quedar meridianamente claro cuando en la inspección al cuarto del Procurador - auténtico archivo de la institución jesuítica- del Colegio se halló un testimonio de Juan Antonio Montes escribano de S.M. y Theniente de la escribanía de Cámara de la Contratación de Cádiz en razón de los autos remitidos a ella con motivo de la muerte de Dn. Pedro Negrette por el que se expresa que entre los Legados del citado D. Pedro hera uno de veinte y cinco mill Pessos para el rehedificio y augmento de la Ya Parrochial de $S^{n}$ Barttme de el Lugar de Aldeacueva en el Valle de Carranza (sic) ${ }^{58}$

Sin embargo, la retención de los caudales no era infrecuente entre los jesuitas, elegidos por muchos comerciantes de las colonias para hacer llegar sus envíos a España. Los procuradores de los colegios solían dilatar la entrega de las remesas a sus destinatarios finales en periodos que iban de treinta a cuarenta años, destinando los capitales al crédito a particulares, ${ }^{59}$ que es lo que pudo ocurrir con el legado Negrete.

A mediados de junio se inspeccionaría la bodega donde

54 Burrieza Sánchez 2003: 10.

55 Sánchez Barea 2011. En el caso de algunos colegios de Castilla se llegó a fijar una cantidad mínima de 21.000 ducados para poner en marcha las distintas iniciativas que surgieron a finales del siglo XVI. Vid. Burrieza Sánchez 2007: 115-118.

56 Cofiño 2008.

57 Ibídem: 305.

58 A.H.P.C. Sección C.E.M. Libro 53, fol. 85 vta.

59 López Martínez 2000. se encontraron tres carrales, uno con 322 litros de vino tinto de Rioja, otro con 242 de vino blanco de la Nava del Rey y el último con 65 litros de vinagre, tasado todo ello en 826 reales. A continuación se pasó a la despensa en la que quedó reflejada la alimentación básica de los jesuitas, predominando sorprendentemente los frutos secos y los pasos: nueces, avellanas, almendras, ciruelas y uvas pasas (pasas de sol), orejones, además de aceitunas. También se encontró tocino, manteca (no se especifica si de vaca o de cerdo), garbanzos y alubias, más ocho arrobas de aceite. Ninguna alusión a pescados - que podían tomar frescos dada la condición portuaria de Santander - ahumados, salados o en conserva. Por último, en la despensa se hallaron seis tinajas para aceite, aunque en esos momentos solo una contenía seis arrobas. No se encontraron productos lácteos en ese momento. Sin embargo, veremos que esos alimentos debían elaborarse en Torres, ya que poco después se vendieron distintos objetos procedentes del extinguido colegio, entre los que se encontraban distintos víveres como más de un centenar de quesos procedentes de la "casería de Torres", así como casi medio centenar de cabras y cabritos y una docena de cerdos de la misma procedencia. De la sede santanderina se vendieron 139 fanegas de trigo, cereal que tampoco había aparecido en el inventario inicial. ${ }^{60}$

Además de la falta de cualquier tipo de pescado, tampoco se halló rastro alguno de carne fresca o tratada de forma conservante. Sin embargo, en la caballeriza (hay que tomar el término "caballeriza" en su acepción montañesa de "establo") que estaba junto a las escuelas había 64 carneros castellanos y dos cabras. Sin duda los primeros debían constituir la reserva de carne de la comunidad y las cabras podían surtirles de leche. Quizá las 26 cabezas de vacuno mayores y menores de la granja de Torres realizasen la misma función, junto a otros abastecimientos ya que junto a estas últimas, había otros animales como cerdos y cerdas de distintas edades y gallinas. Tenían también almacenados 170 celemines de maíz. ${ }^{61}$ En la casería de Güemes había también algunas cabezas de ganado: una vaca, dos novillos, dos bueyes, 16 ovejas y un carnero, tasados todos ellos en 652 reales. $^{62}$

\subsection{Patrimonio inmueble}

El día 25 de junio se dará paso a realizar el inventario de las propiedades inmuebles del Colegio, tanto de Santander, como de otras zonas. El núcleo de las propiedades inmuebles de los jesuitas santanderinos se encontraba en la propia ciudad. Quince casas situadas en el centro de la población, junto a la catedral o en el entorno del Colegio, tasadas en la elevada cifra de 301.778 reales, constituían la parte del león de sus propiedades inmuebles. Conocemos la identidad de sus inquilinos, pero no la renta que abonaban por su alquiler. Uno de los edificios sirve para cárcel del Tribunal Eclesiástico. ${ }^{63}$ La más valiosa parecía ser la que

60 B.M.S. Ms. 282. Índice por el orden del Avecedario que comprehende los efectos que se han podido vender de los encontrados en este colegio, y algunos géneros comestibles de los que se compraron para manutención de los regulares, fols. 1-5.

61 A.H.P.C. Sección C.E.M. Libro 53, fols. 23 vta.- 24.

62 A.H.P.C. Sección C.E.M. Libro 53, fol. p. 25 vta.

63 A.H.P.C. Sección C.E.M. Libro 53, fol. 106. 
ocupaba Juan Antonio Aguirre, comerciante santanderino, aunque de origen vascongado. Ocupaba una casa en la calle de la Compañía. Estaba tasada en 95.724 reales, un tercio del valor total de los inmuebles urbanos propiedad de los jesuitas.

Menor estimación, 4.420 reales, tuvo una casa que el Colegio poseía en Güemes. Doscientos reales alcanzó otro edificio que compartían los frailes a medias con el cabildo de la Catedral y en el que se recogían los diezmos de esa población. Aunque no sea más que un indicio, parece que Cabildo catedralicio y Colegio mantenían unas buenas relaciones a la altura del comienzo del último tercio del siglo XVIII. En realidad no hay ni un solo síntoma de que ni con el cabildo, ni con el resto del clero santanderino se hubiera mantenido enfrentamiento o roce alguno a lo largo del más del siglo y medio de permanencia de los ignacianos en Santander, excepción verdaderamente notable en lo que era la respuesta corriente a la llegada de los jesuitas a una localidad en la que ya existiera algún convento o monasterio, como se señaló anteriormente.

En el concejo de Torres, en la jurisdicción de Torrelavega -territorio que estaba bajo la jurisdicción de la Casa Ducal del Infantado- mantenían la propiedad de algunos edificios. La citada más arriba como granja de Torres, el más importante complejo edificado de los jesuitas fura del ámbito santanderino, estaba tasada en 28.635 reales y debía estar gestionada por los propios frailes. Estaba compuesta por la casa, un establo, un gran corral con portalada y una capilla. En su interior había, entre otras estancias, dos habitaciones amuebladas, que debían de estar reservadas a los jesuitas. La casa estaba habitada permanentemente por un casero y dos criados. Es de reseñar, no obstante, que en sus instalaciones había una gran cantidad de madera cortada en tablones, tablas y viguetas de distintos tamaños y grosores. Es posible que estuvieran destinadas a las labores de mantenimiento del colegio, pero no debe descartarse que esa madera fuera comercializada para la construcción de edificios o de navíos. Ello era posible porque la granja de Torres albergaba el monte de La Biesca, una superficie boscosa de unas $20 \mathrm{Ha}$ en la margen izquierda del río Saja en la que crecían 2.000 robles y más de 600 hayas. En la casa de la granja se inventariaron otras dos habitaciones con sendas camas y sus ropas, además de otra cama para un criado. Había también aperos de labranza. Seguramente la granja de Torres podía estar gestionada por dos jesuitas a los que ayudaban los asalariados reseñados más arriba, sin descartar el trabajo de otros trabajadores externos a la hacienda, como parece demostrarlo la existencia de un libro de cuenta en razón de los jornales que ganan algunos obreros que trabajan las haciendas de Torres. Las labores de estos trabajadores consistían en el tiempo de siega... en el recogimiento y curación de hierba ya en la limpieza del rio y ya en recoger y limpiar las castañas y demas menesteres (sic), ${ }^{64}$ por lo que parece evidente que en ella se desarrollaban actividades económicas complementarias y subsidiarias a las realizadas en el colegio de Santander. Además de esta casa y sus instalaciones anejas, los ignacianos poseían en el lugar dos molinos arrendados a

\footnotetext{
64 A.H.P.C. Sección C.E.M. Libro 53, fols. 96 y 102.
}

una vecina del concejo, Javiera Pérez. ${ }^{65}$ En 1752 lo habían estado a Juan de Herrera por 1.200 reales anuales de los que le quedaban líquidos 700 , estando tasados en 28.000 y 32.000 reales respectivamente. ${ }^{66}$

Fuera del marco de la diócesis, la Compañía tenía una casa en Bilbao y otra en Balmaseda. Ambas habían sido propiedad de Francisco de Ayerdi, vecino de Bilbao. Los jesuitas se habían hecho con la propiedad de las dos por una quiebra, sin dar más información al respecto. Aunque no se aportan datos sobre la tasación de ambos inmuebles, sabemos que el inquilino de la casa de Bilbao, José de Ibarra y Aligorri, pagaba una renta de 704 reales anuales. ${ }^{67}$

Además de esa más de una docena de edificios, los jesuitas santanderinos poseían más de centenar y medio de fincas rústicas distribuidas en varios concejos, sobre todo en Santander y Torres, con una superficie total de poco más de 42 Has. La mayor parte de estos predios eran tierras de labor y prados.

Tabla 1

\begin{tabular}{|l|c|c|}
\hline \multicolumn{1}{|c|}{ DEDICACIÓN } & EXTENSIÓN (Has.) & TASACIÓN (reales) \\
\hline Prados & 25,85 & 143.903 \\
\hline Tierras & 12,76 & 61.399 \\
\hline Otros & 3,41 & 18.800 \\
\hline TOTAL & 42,02 & 223.508 \\
\hline
\end{tabular}

\subsection{Rentas}

Junto al patrimonio rústico y al urbano, como otras instituciones y familias sobresalientes de la Cantabria del Antiguo Régimen, el Colegio de Santander se sustentaba sobre un tercer pilar económico: las rentas provenientes de la deuda pública (juros) y privada (censos hipotecarios). En el primer caso nos encontramos sin duda con la huella de las primeras aportaciones de Magdalena de Ulloa. Cuatro juros sobre el $10 \%$ del juro de lanas, dos sobre los millones de las ciudades de Burgos y Ávila y uno sobre el papel sellado, sumando en conjunto 309.414 maravedises. ${ }^{68}$

Más recientes debían ser los 63 préstamos censales que, en conjunto, alcanzaban los 458.498 reales de principal. No se trataba únicamente, como ocurría en el caso de los cenobios masculinos y femeninos de otras órdenes religiosas, de pequeños préstamos a los vecinos de los alrededores, sino de elevadas cantidades adelantadas a ilustres casas nobiliarias o a instituciones como villas y ciudades. Entre los censatarios de los jesuitas santanderinos estaban algunos de los más destacados nobles castellanos: Medinaceli (dos censos de 75.031 y 6.000 reales), Híjar (46.120 reales) y Santa Cruz (33.000 reales). Algunas poblaciones debían igualmente sustanciosas cantidades al Colegio santanderino. Es el caso de la ciudad de Salamanca (66.000 reales), la villa de Sacedón en Guadalajara (22.629) y la vallisoletana de Ataquines (6.000). Solamente en el caso de Sacedón tenemos datos a través de sus Respuestas

\footnotetext{
65 A.H.P.C. Sección C.E.M. Libro 53, fols. 102-102 vta.

66 A.H.P.C. Sección C.E.M. Libro 53, fols. 115-138.

67 A.H.P.C. Sección C.E.M. Libro 53, fol. 150.

68 A.H.P.C. Sección C.E.M. Libro 53, fols. 140-141 vta.
} 
Generales de la deuda a favor del colegio santanderino que conllevaba el pago de 354 reales anuales. ${ }^{69}$ Un aspecto que hay que destacar en la localidad caracense de Sacedón es el dominio señorial de la casa de Infantado, circunstancia que no concurría en los otros casos. El colegio jesuita de Murcia era también deudor del santanderino merced a un censo de 59.000 reales.

En conjunto, pues, el Colegio de Nuestra Señora de la Anunciación tenía a su favor rentas por un valor de 458.498 reales en censos hipotecarios y 318.823 maravedises en juros situados sobre distintos tipos de impuestos. Aunque no es posible conocer con precisión en qué épocas se obtuvieron estas cantidades, no es descabellado situarlas en el caso de los juros en la primera época de la aparición de los jesuitas en Santander y, por lo tanto, serían rentas concedidas por Magdalena de Ulloa, como se ha apuntado más arriba, en el momento de la fundación del Colegio, mientras que en el de los censos hipotecarios, la atribución de las diversas cantidades es mucho más incierta, pero lo más probable es que los de mayor volumen fueran concedidos en la época en que el marqués de Villapuente se convirtió en el protector de la entidad, amén de que muchos de ellos, sobre todo los de menor cuantía, se habrían concretado como consecuencia de la propia dinámica económica del Colegio, tal y como ocurría con otros centros religiosos del territorio montañés.

\subsection{Una "empresa" bien gestionada}

Sin embargo, parece claro que el Colegio de Santander no era un monasterio o un convento más. Pese a su escaso desarrollo temporal - poco más de siglo y medio desde su apertura-, por la suma de sus propiedades rústicas y urbanas y por sus niveles de rentas, superaba con creces a entidades eclesiásticas con trayectorias que trascendían los dos siglos. Desde luego había alcanzado un desarrollo económico mucho mayor que los cenobios - femeninos y masculinos - de estirpe franciscana, que sí debieron respetar en Cantabria el designio de su fundador de evitar la acumulación de riquezas. Pero sorprende que también los dominicos y los benedictinos fueran sobrepasados por los jesuitas en lo que a bases materiales se refiere; algo nada extraño si se tiene en cuenta que en algunos ámbitos del orbe católico eso ya había tenido lugar, como es el caso de Chile, en donde en 1767 «su fortuna era superior a lo menos en el doble a la de todas las órdenes, reunidas, aun comprendiendo en estas últimas a las de todas los monasterios de monjas». ${ }^{70}$

Las desamortizaciones del Trienio Liberal y de Mendizábal son un buen botón de muestra del patrimonio de los cenobios montañeses. A este respecto y dentro de un esquema general del clero regular de la Cantabria de la época, hay que indicar dos aspectos; en primer lugar, la debilidad de los patrimonios del clero regular montañés - masculino y femenino- y la superioridad de los bienes en territorio cántabro de los grandes monasterios del norte de Burgos, La Rioja y Palencia. En el caso del clero regular masculino destacaban el monasterio riojano de Santa María

69 A.H.P.C. Sección C.E.M. Libro 53, fols. 141 vta.-146. http://pares. mcu.es/Catastro/servlets/ImageServlet Respuesta 26, fol. 690 vta.

70 Bravo Acevedo 1995. la Real de Nájera y el burgalés de San Salvador de Oña, junto con las fincas de la abadía de Covarrubias. Si apuntamos hacia el clero femenino, debemos destacar el convento de las clarisas de San Pedro del Arroyo, situado en el norte de Palencia. ${ }^{71}$

$\mathrm{Si}$ nos centramos exclusivamente en los radicados en Cantabria, comprobamos que el mayor propietario era el convento dominico de Nuestra Señora de Montesclaros, situado en la comarca campurriana lindante con el norte de Burgos, con un patrimonio rústico desamortizado de 84,05 hectáreas en la etapa Mendizábal. Unos bienes de similar extensión $(87,56$ hectáreas) fueron subastados en el anterior proceso del Trienio perteneciente al convento jerónimo de Santa Catalina de Corbán, cercano a Santander. Por último, cabe destacar las 45,63 hectáreas del monasterio benedictino de Santo Toribio de Liébana, ya a gran distancia de los dos anteriores, de las que más de 41 correspondieron a un único monte. ${ }^{72}$

Midiendo el impacto desamortizador en la propiedad inmueble urbana, vemos que en Santander se produjo la mayor concentración de edificios subastados. En lo que se refiere a las casas se vendieron 24 viviendas, de las 94 que se remataron en toda la provincia de Santander, y 3 bodegas alcanzando un valor de 3.209 .563 reales, habiendo sido tasadas en 1.689 .533 reales. $^{73}$ Creemos que, tras la expulsión de los jesuitas, el cabildo de la Catedral se hizo cargo de sus casas. Nos inclinamos a pensar, pues, que una parte sustancial del patrimonio inmueble perteneciente al cabildo y subastado entre 1837 y 1848 , procedía en realidad del extinto colegio jesuítico.

Volviendo la vista a las rentas y, especialmente, a los censos al quitar del que los jesuitas habían prestado 63 con un capital de 458.498 reales, comprobamos - utilizando el mismo método de compararles con los más destacados poseedores de censos desamortizadosque el mayor censualista de los conventos montañeses en el momento desamortizador fue el franciscano de Laredo, del que procedían 178 censos (el 22,08\% del total de los desamortizados) que constituyeron un principal de 187.501 reales (el $22,13 \%$ de los capitales prestados). Algo por debajo se encontraban los censos que habían sido propiedad del también convento franciscano de la Virgen del Soto, en el valle de Toranzo (215 préstamos y 152.994 reales). Los franciscanos y las clarisas mantenían el mayor número de censos hipotecarios a su favor, posiblemente por la prohibición de sus reglas de acumular patrimonio inmueble. Muy por debajo de los 100.000 reales prestados se encontraba el resto de los cenobios montañeses. ${ }^{74}$

En el mismo proceso desamortizador de Mendizábal se subastaron, procedentes de los "ex-jesuitas", 34 censos con un principal de 33.402 reales, ${ }^{75}$ un pálido reflejo de los valores relativos a los préstamos concedidos por los jesuitas antes de 1767.

A la luz de estos datos, es posible afirmar que el Colegio de Jesuitas de Santander, era una de las instituciones religiosas más poderosas de Cantabria en los albores de

\footnotetext{
71 Sánchez Gómez 1994: 170-171

72 Ibídem: 174-175.

73 Ibídem: 180-181.

74 Ibídem: 183-188.

75 Ibídem: 186.
} 
la crisis del Antiguo Régimen. Posición que, sin duda, se hubiera incrementado si el proceso no se hubiera detenido en 1767.

Una vez realizado el inventario del patrimonio inmueble del Colegio y de los préstamos que había realizado, se procedió a elaborar la relación de deudas que la institución tenía a su favor. Ello permite ponderar el estado económico efectivo de los jesuitas santanderinos, ya que los datos se recopilaron en función de la situación de los deudores, lo que implicaba conocer a "tiempo real" la verdadera situación financiera del Colegio en estos cuatro conceptos:

- Ingresos por intereses de los juros.

- Ingresos en concepto de intereses de los censos hipotecarios.

- Ingresos por arrendamientos de fincas rústicas.

- Un cuarto concepto en el que hemos incluido ingresos no encajados en los tres anteriores.

Había también un capítulo dedicado a las deudas difícilmente cobrables, cuyo monto total era de 13.409 reales. Puede considerarse que esta cantidad era la suma de los atrasos, por lo que no podrían integrarse claramente en los anteriores conceptos.

Tabla 2

\begin{tabular}{|l|c|}
\hline \multicolumn{1}{|c|}{ CONCEPTO } & CANTIDAD (reales) \\
\hline Intereses de los juros & 17.882 \\
\hline Intereses de los censos hipotecarios & 54.146 \\
\hline Ingresos por arrendamientos rústicos & 991 \\
\hline Otros & 1.215 \\
\hline TOTAL & 74.234 \\
\hline
\end{tabular}

No aparecen en la información recogida los ingresos provenientes de los arrendamientos urbanos. Podría parecer muy baja la cantidad debida a los alquileres de fincas rústicas, pero debe tenerse en cuenta que la mayor parte de las tierras, prados y bosques debían ser explotados directamente por los frailes.

Así pues, el producto de rentas y arrendamientos superaba los 74.000 reales anuales, a lo que habría que añadir otros ingresos de difícil evaluación como limosnas, ventas de productos agrícolas y ganaderos u otros. En el inventario que se realizó en el archivo y que creemos fue exhaustivo, no aparece ninguna otra fuente de ingresos. Sin embargo no están incluidas las cantidades ingresadas en concepto de diezmos de los lugares de Güemes, Pontones, Galizano y Castanedo. Ni tampoco, lo que es mucho más llamativo, los ingresos que debían obtener por las 15 casas que poseían en Santander y que habían sido tasadas en 301.778 reales, todas ellas situadas en las calles más céntricas de la ciudad, alguna de las cuales - como la que ocupaba el descollante comerciante Juan Antonio de Aguirre- alcanzó en la tasación los 95.724 reales. Suponemos que las cantidades por el alquiler redondearían los ingresos de los jesuitas hasta cerca de los 100.000 reales anuales.

A lo largo del inventario no aparece en ningún momento el concepto de "venta de bienes" que sí se reseña, en cambio, en el único libro conservado que recoge los movimientos mensuales de dinero, el correspondiente a la primera mitad del siglo XVII, ${ }^{76}$ aunque el análisis exhaustivo de su contenido no se pueda incorporar aquí por su prolijidad y para no desbordar con ello los límites adecuados para este trabajo. El interés central de este documento es que recoge el estado económico del Colegio en los primeros pasos de su creación. Uno de los aspectos más interesantes es la constatación del hecho de que los jesuitas vendían regularmente los bienes agropecuarios y forestales que producían o los subproductos de los alimentos que consumían. Así, una de las mercancías que se vendían mensualmente eran los "pellejos", "vientres", "menudos" y "asaduras" y, a medida que avanzaba la centuria, las "cabezas" de los carneros que sin duda formaban parte de su dieta. Un mes con otro vendían entre 26 y 28 pellejos, lo cual indica que la carne de carnero formaba parte de la alimentación cotidiana de los ignacianos, quizá con una media diaria de una res para los entre 16 y 18 frailes que habitaban el Colegio en esa época. A medida que avanzaba el siglo se incorporó la carne de vacuno (terneras, las crías de las vacas). Además, a partir de los inicios de los años 40 de esa centuria, no solo vendían los despojos, sino que lo hacían con los propios animales, puesto que abastecían al obligado del abastecimiento de la carnicería concejil de la villa santanderina de carneros y terneras, sobre todo en los meses finales del año. Un producto más esporádicamente comercializado era la "manteca" (tocino) de cerdo. Parece que la mayoría de los animales y sus productos vendidos provenían de los propios hatos de los jesuitas que criaban en la extensa finca de Castillo, en la granja de Torres -en esta última el vacuno- o en la propia huerta del Colegio. Sin embargo, los productos de los que obtenían más ingresos eran los cítricos. En algunos años su venta superaba los 20.000 limones y las 2.000 naranjas, ambos muy cotizados en un puerto puesto que las tripulaciones tenían muy escasos medios alternativos para combatir el temido escorbuto. ${ }^{77}$ Algo similar debía ocurrir con las ventas de hortalizas, aunque en menores cantidades que los limones y las naranjas.

Otra de las mercancías que vendían eran las maderas elaboradas en forma de tablas, tablones, vigas y viguetas. Seguramente destinadas a la construcción de edificios, también podrían tener uso en la fabricación o reparación de barcos de distinto tamaño y porte que se realizaba en las atarazanas a escasos metros del propio colegio. No obstante, en algunas ocasiones la venta de piezas de madera estaba destinada a otros menesteres, como ocurrió en octubre de 1638 en que se vendieron por 72 reales 16 tablones de nogal y 2 de roble para la esplanada y la artillería del castillo de Hano (sic) ${ }^{78}$

Una circunstancia que también se ha comprobado es que muchos colegios fueron abastecedores de productos locales a otras instituciones de la orden, especialmente

76 B.M.S. Ms. 840. Libro primero de las cuentas del colegio de la Compañia de Jesus de Santander (sic).

77 El escorbuto y las enfermedades intestinales asociadas a la enfermedad, provocaba que casi el $25 \%$ de los marineros del puerto santanderino fueran declarados "inútiles para el servicio" en el periodo 1774-1800. Vid. Sánchez Gómez 2009: 179-180.

78 B.M.S. Ms. 840 , fol. 87 vta. 
en los virreinatos americanos. ${ }^{79}$ En el caso del colegio santanderino de la Anunciación también se registraba el abasto de escabeches a los colegios de la Provincia de Castilla a partir del año 1645. El gasto de 281 reales en Aceyte, sal y vinagre con otros aderezos para los escabeches que se remitieron a Castilla...que se abonan por haberse cargado esta cantidad a los Colegios donde se remitio, los cuales a su tiempo satisfarán a este... ${ }^{80}$ ese primer año, comercio que continuó incrementándose en años posteriores.

También se revisaron los "aposentos" donde vivían los jesuitas. Ello nos permite acercarnos algo más a los niveles de vida de sus habitantes. No aparecen en ningún caso las dimensiones de las estancias, únicamente se hace relación del mobiliario y de otros objetos contenidos en ellas, más la tasación de los mismos. Salvo alguna excepción, que se señalará más adelante, el mobiliario estaba compuesto por una cama, una o dos mesas de distinto tamaño, la más grande con cajones, varias sillas - entre cuatro y seis - de baqueta de Moscovia claveteadas y algún taburete de madera. Se añadía un atril para escribir y una o dos alacenas con cajones. Además del capítulo de muebles, se inventariaron en las estancias de los jesuitas una gran cantidad de imágenes religiosas pintadas en todo tipo de soportes: lienzo, papel y cobre. Solían ser de la Virgen, especial predilección tenía la Virgen de la Leche, o de Cristo, sobre todo el Ecce Homo. Pero sobresalían aquellas imágenes del santoral jesuítico: San Ignacio de Loyola, San Francisco Javier, San Francisco de Borja, San Estanislao de Koska, San Luis Gonzaga o los Mártires de Japón, entre otros. En casi todos los aposentos se encontraron uno o varios mapas, aunque en la mayoría de los casos, no se reseña cuál era el territorio representado.

Especial interés para la comisión tenían las ventanas y sus vidrios. El inventario de cada estancia, incluidas otras como la iglesia, el refectorio o la escuela de Gramática comenzaba contabilizando el número de "bastidores" marcos de las ventanas - y sus cristales. Parecían ser los objetos más valiosos de cuantos se inventariaban.

En el caso de las habitaciones de los frailes, la tasación de los objetos contabilizados fluctuaba entre los 300 y los 400 reales. Hay alguna excepción a estos valores, como fue el caso de los objetos contenidos en el "aposento" del P. Joaquín Luengo en el que apenas se alcanzaron los 200 reales de tasación. No obstante, no se valoró un arca que no se abrió y en la que figuraba el rótulo Congregación de Estudiantes de Gramática. $^{81}$ En la distribución de las estancias interiores se contabilizaron cuatro piezas, una para "menores", una segunda para "medianos" y otras dos para "Philosophia" y "Theologia", respectivamente. Sin duda se trataba de estancias utilizadas para la enseñanza en sus distintas etapas. Pero también se inventarió una casa de un alto, y a quatro aguas que tiene su entrada por la huerta de dicho colegio y se halla al norte de él la qual es nueva y servía para las escuelas de Niños. Sin embargo, estas no debieron ser las primitivas instalaciones destinadas a la docencia ya que el mismo día se inspeccionó una gran pieza de dos altos que servia de paxar y llaman casa de las escuelas

79 Sánchez Andaur 2011: 219-220. En Venezuela, el Colegio de Caracas enviaba cacao cultivado en sus haciendas a los religiosos de Santo Domingo. Vid. Torres Sánchez 2017: 272.

80 B.M.S. Ms. 840, fol. 137.

81 A.H.P.C. Sección C.E.M. Libro 53, fol. 39. viexas; $y$ assi mismo... ${ }^{82}$ En cada una de las cuatro primeras estancias destinadas a la enseñanza se encontraron bancos, mesas y cátedras, además de cuadros con pinturas de las distintas advocaciones de la Virgen María. El Rector era en el momento de la expulsión José Isidro García. ${ }^{83}$

No se ha encontrado más documentación de esta agrupación de estudiantes. Sabemos, no obstante, a través de las aportaciones de Martínez Naranjo, la importancia que los jesuitas le daban a la educación de los jóvenes que estudiaban en las aulas de sus Colegios, en las que a la vez de formarse intelectualmente se educaban en las reglas de la moral cristiana. En las escuelas de la orden podían ingresar alumnos de distintos estratos sociales, habida cuenta de la gratuidad de estos estudios. Bajo una rígida normativa, estas asociaciones buscaban ante todo la salvación, por distintos medios, de sus integrantes, sin olvidar extender las prácticas salvíficas a su entorno familiar y de amistades, además de asistir a pobres enfermos en los hospitales, entre otras obras de caridad. ${ }^{84}$ En la Cantabria de la época, hasta su expulsión, el colegio de la Compañía fue la única institución pedagógica de cierta solidez en la Montaña, ${ }^{85}$ dado que el colegio de los escolapios de Villacarriedo, fundado en 1746, apenas había comenzado su labor educativa.

En sus primeros compases, la institución jesuítica ofrecería poco más que las Humanidades Clásicas (tres cursos de Gramática Latina y uno de Humanidades). Además se darían clases de primeras letras. ${ }^{86}$

Pero el inventario de edificios y estancias interiores parece demostrar que el santanderino Colegio de la Anunciación desarrollaba ya todo tipo de enseñanzas como las ofrecidas por la mayoría de los institutos ignacianos ${ }^{87}$

El padre Joaquín Luengo era, en el momento de la expulsión, maestro de Gramática en el Colegio santanderino. Nacido en 1733 en la villa vallisoletana de Nava del Rey, era hermano de uno de los más célebres jesuitas —el P. Manuel Luengo, autor de unas memorias del exilio jesuítico-. Joaquín tenía entonces 34 años cuando le sorprendió la expulsión, siendo el encargado de organizar el embarque de los casi 300 jesuitas que se habían concentrado en el puerto santanderino en abril de 1767. Ocupaba también el cargo de "Ministro" de la casa de Santander. Había ingresado en la compañía en junio de 1752, a los 19 años, en el momento de mayor influencia jesuítica en España, con el P. Francisco de Rávago en el confesionario de Fernando VI. Moriría en 1795 , siendo enterrado en Bolonia. ${ }^{88}$

Solamente tres estancias superaban el valor límite de los 400 reales para los objetos contenidos en ellas. Uno era el "Aposento № 1" en el que había habitado el Rector del Colegio. Los objetos de todo tipo alcanzaron en este caso una tasación de 1.317 reales. Dormía en una cama con dosel. Tenía tres mesas, trece sillas de baqueta de Moscovia claveteadas, dos escritorios y tres taburetes, entre otros muebles. También se inventarió un armario en el que se encontraron diversas prendas de ropa, casi toda ajuar de

\footnotetext{
82 A.H.P.C. Sección C.E.M., fols. 26 vta.-27

83 A.H.P.C. Sección C.E.M., fol. 57.

84 Martínez Naranjo 2002.

85 Fonseca Montes 1996: 230.

86 Fernández Martín 1998: 67.

87 Pérez Picón 1983: 34-37 y 85-92.

88 Fernández Arrillaga 2002: 22-24.
} 
dormir. Además disponía de otros objetos como anteojos de larga vista, ambos desmontados, dos relojes de arena, etc..$^{89}$

La profusión de mesas y sillas, no solo en este, sino en todas las habitaciones de los padres jesuitas, permite aventurar que quizá parte de la docencia se desarrollara en pequeños grupos, aunque también pudieran celebrarse reuniones de contenido religioso.

En otra estancia, la ropería (Aposento no 5), se guardaban, además de las prendas textiles que habían pertenecido a los frailes del colegio santanderino, también las de los demás de las provincias. ${ }^{90}$ Una función similar, pero en la que se conservaban todos los efectos de cobre, yerro, metal, estaño y oja de lata, y otros objetos no metálicos, no solo lo que había en el Colegio sobrante de los que se embarcaron, era el Aposento no 6. ${ }^{91}$ La tasación de todos estos objetos superaban los 5.000 reales en ambos casos.

La relación de bienes del Colegio de la Anunciación, según las declaraciones en el Catastro de la Ensenada, nos ofrece un paisaje netamente distinto a lo que se refleja algo más de una década más tarde. En 1752 los jesuitas tenían en el ámbito santanderino un patrimonio rústico de 8,93 hectáreas en su mayor parte prados $(8,18)$, a los que había que añadir cinco casas, tres molinos y una caballeriza por los que ingresaban 1.787 reales por su arrendamiento, que se completaban con los intereses de 22 censos prestados a vecinos de Santander que, con su principal de 54.097 reales, debían procurar unos ingresos anuales al colegio de 1.622 reales y los intereses de 578.128 maravedises de cinco juros. ${ }^{92}$

Son cantidades claramente inferiores que las que se derivaron del inventario de 1767 . Ello parece conducir solamente a dos explicaciones. En primer lugar, a un claro ocultamiento de bienes a los oficiales del Catastro, pero en segundo lugar, podría explicarse en función del crecimiento de la actividad económica provocada por la serie de cambios que sufrió Santander a partir de la conversión en sede obispal y al consecuente paso, al año siguiente, de villa a ciudad, a lo que habría que añadir en esas mismas fechas la conclusión del camino de Reinosa, que ponía al puerto en contacto con las comarcas cerealeras castellanas y los mercados ultramarinos. Todo ello provocó, sin duda, un claro desarrollo demográfico y económico, por lo que no es extraño que el aumento de los préstamos y del patrimonio urbano se debiera a estas circunstancias, si bien es verdad que en poco más de una docena de años que mediaron entre 1752 y 1767 el crecimiento debió de ser bastante contundente.

\section{CONCLUSIONES}

El expediente realizado con motivo de la expulsión de los jesuitas de Santander, junto con otras fuentes, permite acercarse a algunos de los aspectos más significativos de las condiciones de vida de sus habitantes en el momento de su expulsión, si bien es cierto que la documentación conservada es muy fragmentaria, aunque altamente indicativa.

\footnotetext{
89 A.H.P.C. Sección C.E.M. Libro 53, fols. 31-36.

90 A.H.P.C. Sección C.E.M. Libro 53, fols. 49 vta.-51 vta.

91 A.H.P.C. Sección C.E.M. Libro 53, fols. 51 vta.-55.

92 Archivo Municipal de Santander. Sección Hacienda. Leg. B-73,
} fols. 2-11.
Un colegio fundado a finales del siglo XVI en un proceso que tuvo dos etapas. La primera, en la que una de las más conspicuas damas de la añeja nobleza castellana se convirtió, merced al fallecimiento de su marido — Luis Méndez de Quijada-, en uno de los más firmes apoyos de los jesuitas a finales del siglo XVI. La segunda etapa, en la que de manera muy paradigmática, el relevo de Magdalena pasará a manos de un prototípico miembro de un nuevo grupo social surgido a raíz del fortalecimiento de los lazos de la metrópoli castellana con los territorios ultramarinos desde finales del siglo XVII. Será un representante del extenso grupo de comerciantes, mineros, hacendados, militares o integrantes de la administración borbónica ultramarina -en algunos casos sus integrantes reúnen simultáneamente algunas de las actividades anteriores-, José de Villapuente, que, como algunos de sus homónimos sociales, ascenderán a los más altos estratos de la nobleza impulsados por sus actividades económicas y por sus servicios a la Corona. Tanto Magdalena como José, pusieron la mayor parte de su patrimonio a disposición de los jesuitas traspasando, sobre todo este último, largamente el marco peninsular de la Corona. Un colegio, pues, que sintetiza a lo largo de su trayectoria el apoyo que las clases sociales más destacadas prestaron a muchas de las instituciones ignacianas.

Su corta andadura, apenas siglo y medio, no impidió a los jesuitas convertir a la institución en una empresa próspera y saneada. Los datos que se han manejado, así parecen indicarlo. Santander, desde la llegada de los discípulos de San Ignacio a la villa hasta su expulsión, había sufrido, e iba a seguir sufriendo, una profunda transformación que convirtió a una villa portuaria menor, insertada en el centro de la cornisa cantábrica, en uno de los epicentros del comercio ultramarino del último tercio del siglo XVIII. Una situación a la que no fueron ajenas las medidas tomadas por Fernando VI, más bien por el círculo ensenadista, una de cuyas figuras más destacadas era el confesor real, el jesuita Francisco Rábago, originario del remoto pueblo de Lombraña situado en las profundidades montañosas de la Cantabria de la época.

Con el apoyo de sus fundadores y el de cientos de congregantes, distribuidos a lo largo y ancho del territorio montañés, pero sustentado sobre todo con lo que debió de ser una exhaustiva y atenta administración, el Colegio santanderino de la Anunciación se convirtió en una próspera empresa que desarrolló múltiples formas de actividad económica. Desde la venta de productos propios, pasando por la compra de tierras y edificios, o por los préstamos hipotecarios, créditos que alcanzaban incluso a algunos de los Grandes castellanos. La compra y posterior alquiler de edificios en Santander y de fincas rústicas en los alrededores de la ciudad y en otros puntos de Cantabria, también constituyeron piezas claves en el desarrollo económico del Colegio. De estas tierras obtenían parte de los bienes que vendían: cítricos, otros productos agrícolas y ganaderos, además de objetos elaborados con la madera de sus bosques.

Sin duda una empresa bien engrasada y bien administrada que sobresalía por encima del resto de las instituciones eclesiásticas regulares, más bien enfocadas a los préstamos hipotecarios y al arrendamiento de sus magras propiedades. De ello es muestra el control que los rectores de la Provincia de Castilla ejercían sobre las cuentas 
de cada colegio. En el de Santander, a finales de cada año entre los meses de octubre y noviembre, el correspondiente visitador examinaba las cuentas del colegio, apreciándose una especial atención a las deudas a favor del Colegio y a los gastos extraordinarios.

Pero este proceso de expansión económica se quebró justamente cuando las medidas "liberalizadoras" del comercio ultramarino promovidas en el reinado de Carlos III comenzaban a dar sus frutos. Cabría entonces preguntarse cuál hubiera sido la trayectoria del colegio jesuítico. Es difícil imaginar si la institución hubiera continuado su expansión territorial y económica en el último cuarto del siglo XVIII y las primeras décadas del XIX en una Cantabria donde no solo se estaba asentando una naciente burguesía comercial de diversas procedencias, sino que las elites tradicionales, nucleadas en torno a una influyente y poderosa hidalguía rural, se estaba reposicionando a medida que el sistema antiguorregimental entraba en crisis, adhiriéndose a muchas de las medidas que la Corona puso en marcha en ese periodo. No en vano ambos grupos - muchas veces fundidos en uno solo a partir de enlaces matrimoniales y alianzas económicas - acudieron masivamente a la pignoración de los bienes eclesiásticos y paraeclesiásticos - capellanías, cofradías o fundaciones benéfico-docentesen las sucesivas desamortizaciones desde la de Godoy hasta la de Mendizábal.

La expulsión decretada en abril de 1767 yuguló la trayectoria de una institución que había creado todo un complejo económico sobre el que se basaba el resto de sus actividades pastorales, entre las que la enseñanza ocupaba un lugar preferente.

\section{FUENTES}

Archivo Histórico Provincial de Cantabria. Sección Centro de Estudios Montañeses. Libro 53.

Archivo Municipal de Santander. Sección Hacienda. Legajo B-73.

Biblioteca Municipal de Santander. Ms. 282. Índice por el orden del Avecedario que comprehende los efectos que se han podido vender de los encontrados en este colegio, y algunos géneros comestibles de los que se compraron para manutención de los regulares.

Biblioteca Municipal de Santander. Ms. 840. Libro primero de las cuentas del colegio de la Compañía de Jesús de Santander.

\section{BiBLIOgRAFÍA}

Alcaraz Gómez, J. F. 1995. Jesuitas y reformismo. El Padre Francisco de Rávago (1747-1755). Valencia: Facultad de Teología San Vicente Ferrer.

Atienza López, A. 2009. «Nuevas consideraciones sobre la geografía conventual en la España Moderna. Otras facetas más allá de la concentración urbana». Hispania Sacra 123: 51-75.

Benito Aguado, T. 2001. «La resistencia al asentamiento de los jesuitas en el País Vasco (1583-1751)», en R. Porres Marijuán (ed.). Poder, resistencia y conflicto en las provincias vascas (siglos XV-XVIII): 339-365. Bilbao: Universidad del País Vasco.

Bernabéu Albert, S. 2011. "Desatar al demonio". La resistencia de los indígenas sudcalifornianos al proyecto misional jesuita (1721 1767)», en F. Langue (coord.) Fronteras y sensibilidades en las Américas: 151-180. Madrid: Ediciones Doce Calles.
Bravo Acevedo, G. 1995. "Historiografía de la empresa económica jesuita en Hispano América colonial». Universum 10: 5-21.

Burrieza Sánchez, J. 2003. "La recompensa de la eternidad: los fundadores de los colegios de la Compañía de Jesús en el ámbito vallisoletano». Revista de Historia Moderna. Anales de la Universidad de Alicante 21: 29-56.

Burrieza Sánchez, J. 2004. "Los ministerios de la Compañía», en T. Egido (coord.), Los jesuitas en España y en el mundo hispánico: 107-148. Madrid: Fundación Carolina - Marcial Pons.

Burrieza Sánchez, J. 2007. Valladolid, tierras y caminos de jesuitas. Presencia de la Compañía de Jesús en la provincia de Valladolid, 1545-1767. Valladolid. Diputación de Valladolid.

Burrieza Sánchez, J. 2009. «Los jesuitas: de las postrimerías a la muerte ejemplar». Hispania Sacra 124: 513-544.

Cascón, M. S. I. 1952. «La historia del Colegio de la Compañía de Jesús de Santander, manuscrito del Padre Luis de Valdivia». Altamira 1: 3-27.

Chevalier, F. 1999. La formación de los latifundios en México. Haciendas y sociedad en los siglos XVI, XVII y XVIII. México: Fondo de Cultura Económica.

Cofiño, I. 2008. "Los Negrete, promotores artísticos y benefactores del Valle de Carranza», en Modelos, intercambios y recepción artística (De las rutas marítimas a la navegación en red). XV Congreso Nacional de Historia del Arte (CEHA): 299-309. Palma de Mallorca: Universitat de les Illes Balears.

Egido, T. (coord.). 2004. Los jesuitas en España y en el mundo hispánico. Madrid: Fundación Carolina - Marcial Pons.

Fernández Arrillaga, I. Éxodo y exilio de los jesuitas españoles según el diario inédito del P. Luengo (1767-1814). Tesis defendida en la Universidad de Alicante en febrero de 2002 (inédita).

Fernández Martín, L. 1998. "Notas históricas sobre el colegio de la Compañía de Jesús de Santander». Altamira 53: 197-203.

Fonseca Montes, J. 1996. El clero en Cantabria en la Edad Moderna. Un estudio de la implantación de la Contrarreforma en el Norte de España. Santander: Universidad de Cantabria.

Jado Canales, Á. 1957. «Don José de la Puente y de la Peña. Primer Marqués de Villapuente de la Peña», en Banco de Santander, 1857-1957. Aportación al estudio de la Historia Económica de la Montaña: 691-702. Santander: Centro de Estudios Montañeses.

Lanza García, R. 1991. La Población y el Crecimiento Económico de Cantabria en el Antiguo Régimen. Madrid: Universidad Autónoma de Madrid - Universidad de Cantabria.

Lanza García, R. 1994. Camargo en el siglo XVIII. La economía rural de un valle de Cantabria en el Antiguo Régimen. Santander: Asamblea Regional de Cantabria - Ayuntamiento de Camargo.

López Martínez, A. L. 2000. «Los jesuitas y su intermediación financiera en la Carrera de Indias», en A. M. Bernal (ed.), Dinero, moneda y crédito en la Monarquía Hispánica: 751-764. Madrid: Fundación ICO - Marcial Pons.

Martínez Naranjo, F. J. 2002. "Aproximación al estudio de las Congregaciones de estudiantes en los Colegios de la Compañía de Jesús durante la Edad Moderna». Revista de Historia Moderna. Anales de la Universidad de Alicante 20: 227-250.

Pérez Picón, C. 1983. Un modelo ejemplar de letras humanas en Villagarcía de Campos (1576-1767). Madrid: Sal Terrae.

Porres Marijuán, R. 2009. «Las redes mercantiles atlánticas y la instalación de los jesuitas en Bilbao, (1551-1604)», en I. Dubert y H. Sobrado Correa, El mar en los siglos modernos, T. I: 499-511. Santiago de Compostela: Xunta de Galicia.

Porres Marijuan, R. 2012 «Propiedades eclesiásticas en una ciudad aduanera: los jesuitas en Orduña, 1689-1767». Hispania Sacra 129: 309-343.

Puente, L. de la 1615. Vida del P. Baltasar Álvarez religioso de la Compañía de Jesús. Capítulos XXXV y XXXVI. Citado por la versión digitalizada en la Biblioteca Virtual Universal (sin paginar). http:// biblioteca.org.ar/libros/71027.pdf

Rico Callado, F. L. 2003. «Las misiones interiores en la España postridentina». Hispania Sacra 55: 189-210.

Sánchez Andaur, R. 2011. "La empresa jesuítica en el obispado de Concepción: el caso de los colegios San Bartolomé de Chillán y Buena Esperanza». Universum 26, Vol. 2: 215-243. 
Sánchez Barea, F. 2011. «Historia económica del Colegio de jesuitas de Tudela (1600-1767)». Príncipe de Viana 254: 225-235.

Sánchez Gómez, M. A. 1994. La desamortización en Cantabria durante el siglo XIX. (1800-1889) Torrelavega: Ayuntamiento de Torrelavega.

Sánchez Gómez, M. A. 2009. «Las gentes de mar de las Cuatro Villas de la Costa de Cantabria en el siglo XVIII», en I. Dubert y H. Sobrado Correa, El mar en los siglos modernos, Tomo I: 169-185. Santiago de Compostela: Xunta de Galicia.

Sánchez Gómez, M. A. 2013. «La hidalguía rural montañesa en el siglo XVIII. Contrastes comarcales». Investigaciones Históricas. Época Moderna y Contemporánea 33: 107-136.

Sanchiz Ruiz, J. 2009. "Título de Marqués de Villapuente de la Peña a Don José de la Puente y Peña Castexón y Salzines». Estudios de Historia Novohispana 41: 135-149.
Soto Artuñedo, W. 2001. «Fundación del Colegio jesuítico de San Sebastián, en Málaga (España)». Archivum Historicum Societatis lesu 139: 95-171.

Torres Sánchez, J. 2017. Haciendas y Posesiones de la Compañía de Jesús. El Colegio de Caracas en el siglo XVIII. Sevilla: Diputación de Sevilla.

Vergara Ciordia, J. 2011. «Humanidades y profesorado en los jesuitas de Pamplona (siglos XVI-XVII)». Príncipe de Viana 254: 449-463.

Villafañe, J. de 1723. La limosnera de Dios relación histórica de la vida y virtudes de la excelentísima señora doña Magdalena de Ulloa Toledo Ossorio y Quiñones mujer del Excelentissimo señor Luis Mendez Quixada...fundadora de los Colegios de Villagarcia, Oviedo y Santander de la Compañia de Jesus. Salamanca. 